\title{
Effect of a staffing strategy based on voluntary increase in working hours on quality of patient care in a hospital in KwaZulu-Natal
}

\author{
J McIntosh RN M Cur \\ Division of Nursing, Stellenbosch University \\ EL Stellenberg, RN D Cur \\ Division of Nursing, Stellenbosch University
}

\section{Kev words}

safe staffing; accountability; quality patient care; record keeping.

\section{Correspondence address}

Ethelwynn L Stellenberg,

Division of Nursing

Stellenbosch University

\section{Abstract: Curationis 32 (2): 11-20}

Two of the issues facing the South African Health Care System are the shortage of nursing staff and a lack of adequate skills to provide quality patient care. The hospital under study experienced a critical shortage of applications from professional registered nurses, consequently a staffing strategy was implemented to overcome the shortage of nurses and to maintain quality patient care. The strategy introduced encouraged nurses to voluntarily work an additional ten hours per week with remuneration.

A non-expcrimental, descriptive design with a quantitative approach was applied to investigate the effect of a staffing strategy aimed at improving the quality of care in a hospital in Kwa-Zulu Natal based on voluntarily increasing staff working hours. The investigation compared the quality of nursing care before and after the implementation of the staffing strategy through retrospective audits of randomly selected patient files $372(11 \%)$ of the total population of 3400 files were audited.

A random sample of 4 boxes each containing a 100 patient files, of a total of 34 boxes, was selected from the hospital filing system. Descriptive statistical analyses were performed and correlations between various variables using the Chi-square test.

No statistically significant differences $(p<0.05)$ were found between the quality of nursing care before and after the implementation of the management strategy, even though deterioration of results after the implementation was observed.

The study shows that the quality of nursing care in most wards deteriorated after implementation. The staffing strategy failed to improve or maintain the quality of nursing care.

\section{Recommendations included}

Strict control of nurses working extra hours per week, preventing the use of "moonlighters". Introduction of a quality assurance committee to monitor the quality of patient care, developing critical analytical thinking skills of staff to improve patient care and standardization of the nursing process documentation

Tel : (021) 938-9244

Fax : (021) 932-6588

Email: elstel@sun.ac.za 


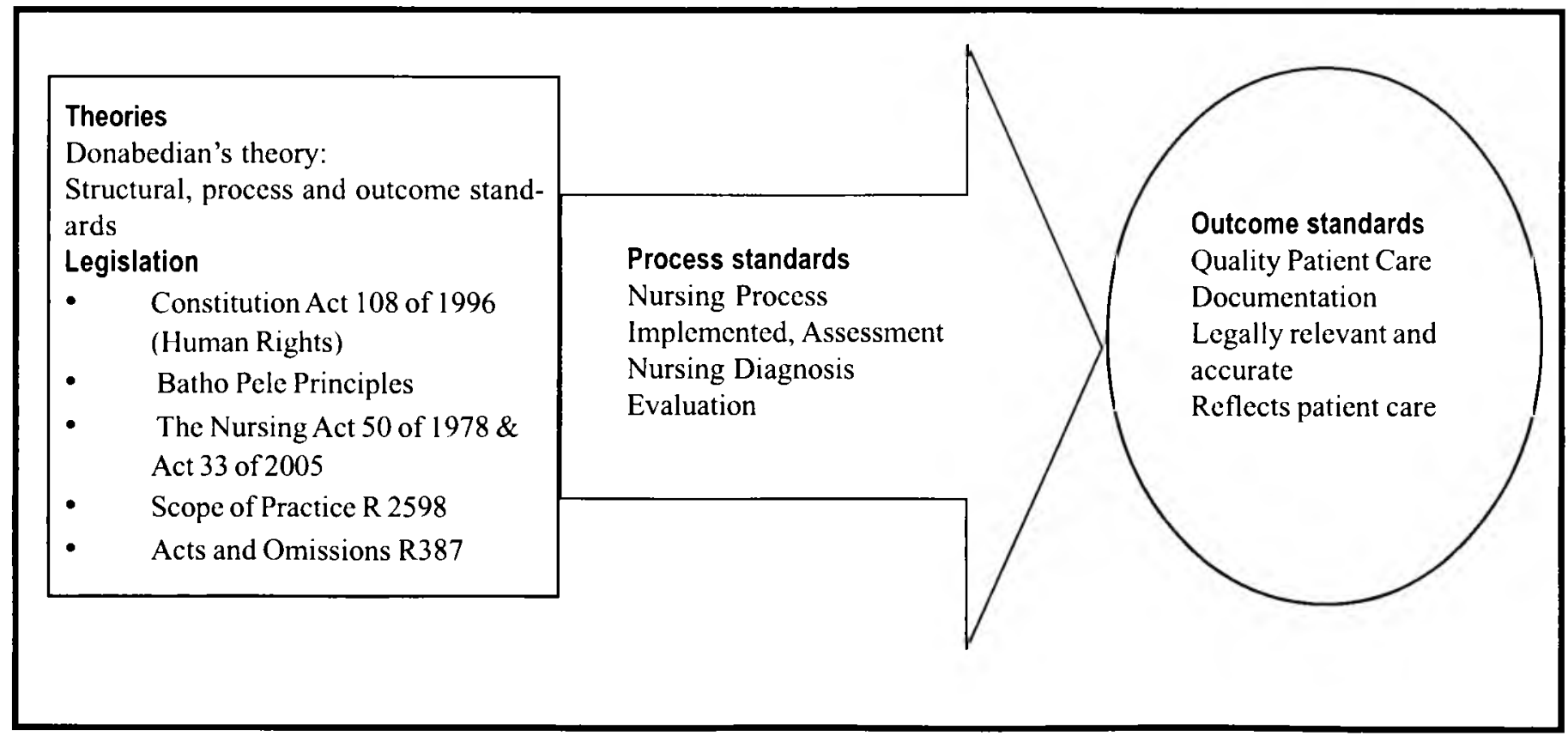

\section{Introduction}

Two of the issues facing the South African Health Care System are the shortage of nursing staff and a lack of adequate skills to provide quality patient care. In June 2003 the hospital under study experienced a critical shortage of applications from professional registered nurses, consequently a staffing stratcgy was implemented to overcome the shortage of nurses and to maintain quality patient care. The strategy introduced encouraged nurses to voluntarily work an additional ten hours per week with remuneration. The South African Nursing Council (SANC) believes that "quality nursing practice is based on adequate knowledge, skills or competencies, ethically and scientifically based comprehensive and holistic patient care, timely/accurate and complete or comprehensive recording" (SANC, n.d: iv).

The conceptual framework of the study was therefore based on Donabedian's framework which has standards divided into structural, process and outcome standards interacting and contributing to the quality of care. Process standards include the steps of the nursing process that are concerned with patient care delivery, assessment, care planning and implementation (Muller, 2004:204-5).

Standard setting and evaluation is used for high-risk nursing activities, such as medication administration, patient discharge, record keeping, patients' progress and infection control. Booyens and Minnaar (2004:309) state that high-risk activities are those, when not done, result in patient trauma, death or litigation. Measuring nursing practice does not have value unless the audited data is communicated to nurses delivering direct care, their immediate supervisors and the organisation's management, in ways that may stimulate remedial action.

As indicated in Figure 1, legislation including the South African Constitution, Act No 108 of 1996, Chapter 2, on Basic Human Rights; the Batho Pele Principles 1997:18340(388); the Nursing Act, No. 50 of 1978, and Nursing Act, No. 33 of 2005; the Scope of Practice R2598 of 30 November 1984 and Acts and Omissions R387 of 15 February 1985 as promulgated by the Nursing Act No 50 of 1978 formed the structural criteria for the study. The nursing process with its phases formed the process criteria while the outcome standards comprised quality patient care, documentation or legally relevant, accurate record keeping reflecting patient care.

A comprehensive literature review was conducted to investigate the conceptual framework and its application in this study.

\section{Legislation}

The South African Constitution, Act 108 of 1996, recognises the basic human rights of all South Africa's people.
Nursing practice is controlled by the Nursing Act, No. 50 of 1978, and the Nursing Act, No. 33 of 2005, as promulgated. Professional registered nurses are accountable for all actions and omissions. In 1997, the White Paper on transforming public service delivery, the Batho Pele Paper, was introduced. It emphasises the improvement of service delivery in the public sector and delivering quality service to all South Africans. Nurse Managers are therefore held responsible for the management of nursing care. Nurse Managers ensure that nurses are provided with safe working environments and have job descriptions enabling them to deliver quality patient care (Searle, $2000: 268$ ). They may be held liable together with their employer, or as individuals for professional malpractice or criminal acts. According to Muller (2004:55), vicarious liability infers that employers are legally responsible for harmful or negligent acts of employees. The legal system holds that if employees are practising within the scope and course of contracts of employment and are negligent, the employer is responsible for payment of any claims incurred. The implication is that employers have a legal liability to provide adequate facilities, staff and equipment for all of their clients (Verschoor, Fick, Jansen \& Viljoen, 2005: 52).

Muller, Bezuidenhout and Jooste (2006:492), agree that employers are responsible for monitoring the competence of health care workers and should 
actively intervene when care is below acceptable standards. Monitoring the quality and quantity of staff is therefore essential. Nurse Managers arc responsible for informing chief executive medical officers when patients are at risk due to understaffing or inadequately skilled staff. Employers and nurse managers ignoring such information become liable for adverse results caused by a lack of remedial action. (Geyer, 2006:46).

Negative incidents decrease when there are more professional registered nurses in the staffing mix (Zondagh, 2004:21). A limited number of studies done on the effect of additional working hours on nurses have shown that relationships exist between extended shifts (more than eight hours) and fatigue as well as increased safety risks. The negative consequences are not limited to physical health, such as fatigue, headache and sleeplessness but also include disruptions and stressed dynamics within social and family life. (International Council of Nurses, 2007a).

Employers' attempts at reducing labour costs may result in inadequate staffing, which could cause unsafe patient care. Hazards that adversely impact nurse retention and recruitment frequently lead to errors that threaten patient safety and negatively affect the patient's treatment outcomes. Evidence consistently demonstrates that patient safety and treatment outcomes are related to staffing (Pronovost, 2002:3 as cited in International Council for Nurses, 2007a).

The Basic Conditions of The Employment Amendment, Act (BCOEA) No 75 of 1997, holds that employees are ethically responsible to themselves, their families, their employers and their patients by ensuring that they have enough rest to perform competent, safe nursing care. Safe quality nursing care becomes impossible when nurses are exhausted (Geyer, 2004:39).

Extensive overtime is also a factor that put patients at risk. Nurses may show errors in clinical judgement, resulting in reduced alertness to changes in patients' condition and slower reactions resulting in medication errors or adverse drug events. (International Council of Nurses. 2007b)

\section{Patient rights}

The Patient Rights Charter (2002) is aligned to the Constitution of South Africa, Act 108 of 1996 which provides for a healthy and safe environment. It is part of a national strategy to ensure access to quality health services delivered to the population. It ensures the right to a standard of patient satisfaction, protects the rights to health and health care, increased accountability, transparency and commitment in the public and private sectors (Muller, 2004:72-3). The introduction of the eight Batho Pele - 'People First' principles in 1997 provides a policy framework and a practical implementation strategy for the transformation of the Public Service to ensure that the right of patients to effective and efficient health care is met.

Patients have a constitutional right to expect nurses to inform hospital managements, in writing, about inadequate staffing to provide quality care (Geyer, 2006:46).

\section{The nursing process}

According to Young, Van Niekerk and Mogotlane (2003:15-16), the nursing process is a systematic process consisting of interaction with individual patients. The phases of the nursing process are: assessment, nursing diagnosis, planning, implementation, and evaluation.

The assessment phase refers to the collection of objective and subjective data. The nursing diagnosis is based on the findings of the assessment phase. Patients' problems, actual or potential, are stated or expressed by patients and/or nurses (Beretta as cited in Hinchliff, Norman \& Schober, 2003: 122).

Nursing care plans are individualized and formulated according to the patient's needs. The desired outcomes aim at solving the identified problems (Young et al., 2003:186-7).

The implementation phase requires nurses to apply their knowledge and skills to determine what care to give and how to care for the patient (Young et al., 2003:16). Nursing care plans are evaluated by a professional registered nurse prior to implementation. Documentation is critical throughout the nursing process and records should be available to all nurses to provide continuous care (Young et al., 2003:191-
4). The evaluation phase enables nurses to determine the efficacy of the entire process of caring for patients.

The nursing process allows for the creation of holistic, individualised care for each patient and has benefits to patients and nurses (Young et al., 2003:182,194). According to Fryer (as cited in Hinchliff et al., 2003:31), it encourages decision making and problem solving.

\section{Qualtiy assurance}

Nursing practice standards are based on "setting, promoting and controlling standards of nursing and midwifery education and practice, monitoring and enhancing the maintenance of ethical standards" (SANC, nd.). It is further based on the Nursing Act No 50 of 1978 , regulations 2598 Scope of Practice and 387 Acts and Omissions as promulgated and newly introduced Nursing Act No 33 of 2005. The Nursing Act and regulations aim to protect the public from unsafe practices and incompetent practitioners. According to Nevhutalu (2004:31), the quality of nursing practice is an ethical issue. Virtues and qualities such as compassion, wisdom, openness, honesty and competence predispose people to do what is right. Professional Registered Nurses are responsible and accountable for the delivery of quality care and should therefore participate in quality assurance processes and advocate for quality care. Patients expect quality care, while employers expect cost-effective quality care (Muller, 2004:53).

Quality in health care is acceptable, accessible, appropriate, effective, efficient and equitable, produced as collaborative teamwork (Frank, Eckrich \& Rohr 1997:13).

Nurse Managers are central to delivering high quality care and is therefore responsible to provide human and material resources.

\section{Accountability}

Nurses must be able to account for their actions and omissions in any situation and take responsibility for the consequences of their actions within their scope of practice (Muller, 2004:55). Nurses must have the skills, knowledge, attitudes and values to be able to perform competently (Muller, 2004:56).

A nurse who neglects to carry out pro- 
fessional responsibilities as prescribed legally can be deemed negligent and cause harm to patients. Consequences for irresponsible nurses may be professional-ethical disciplinary action in terms of R387 of 15 February 1985, Acts or Omissions.

\section{Record keeping}

Record keeping is often neglected when there are insufficient nurses to do the work. This means that nurses fail in their recording of tasks performed and observations made. Actions, effects or findings not recorded are regarded as not done. Failure to record data results in lack of credible quality care delivered to patients. If nurses do not complete these tasks before the end of shifts, they neglect their legal responsibility to patients and themselves, and could be accused of negligence (Geycr, 2006:46).

The SANC warns against taking documentation for granted and states that it must be taught as an integral part of the nursing process (Searle, 2000: 1401). The records provide a foundation for planning, assessing and evaluating diagnostic procedures, treatment and care. It guides the daily management of patients' problems and is a means of communication. Patients trust nurses to ensure their protection through information in written records of care. Poor recording and lack of accuracy, whether done accidentally or purposefully, result in nurses betraying patient trust (Searle, 2000:262).

Records provide a basis for continuity of care, evidence of changes in the patient's condition and prove that care has occurred. It reflects the patient's response to care (Troskie, as cited in Booyens, 2004:352). Additionally, nurses are expected to inform medical practitioners of changes in a patient's condition. Failure to report changes in a patient's condition may be deemed negligent (Verschoor et al., 2005:45).

Record keeping is a professional responsibility that is often neglected.

It is against this background that this scientific investigation was undertaken. For the purpose of this article the effect of the staffing strategy on the quality of care delivered pre and post implementation will be described.

\section{Objectives}

The following objectives were set; to determine whether:

- $\quad$ Patients were adequately assessed

- Nursing diagnoses were made.

- $\quad$ Nursing care plan was based on the findings of the assessment

- Nursing care was implemented

- $\quad$ Patient progress was evaluated according to the nursing prescriptions and interventions, at least twice in 24 hours.

- Discharge report was provided.

\section{Research methodology Research design}

A non-experimental, descriptive design with a quantitative approach (Burns and Grove 2007:540) was applied to investigate the impact of an implemented staffing strategy on the quality of patient care. Patient care was retrospec- tively evaluated by auditing the records of 372 patients who were hospitalised between January 2003 and November 2003.

\section{Population and sampling}

A total of 3400 inpatients were admitted to the hospital during the period between January and November 2003. Files were stored in 34 boxes, containing a 100 files each, with no specific number from any of the wards. A clerk blinded to this study was asked to randomly select any two (12\%) boxes of files of patients who were hospitalized during January-May and two (12\%) boxes from the period of June-November 2003 .

A total of $186(93 \%)$ files were randomly selected from the boxes marked January to May 2003 before the staffing strategy was implemented in June 2003, and $186(93 \%)$ files from June 2003 to November 2003 after the implementation of the strategy (see Table 1 below). A sample N-372(11\%) of the total population of 3400 files were audited.

\section{Audit Instrument}

For the purpose of this study, an audit instrument in use at the hospital was adapted by ensuring that it was specific to the study objectives. The instrument was based on process standards i.e. the phases of the scientific nursing process namely: assessment, nursing diagnosis, planning, implementation and evaluation and discharge. According to the objectives of the study, the audit instrument was divided into the following steps:

Evidence of:

\section{Table 1: Showing the number of files audited per ward pre- and post-implementation}

\begin{tabular}{|l|l|l|}
\hline NAME & $\begin{array}{l}\text { PRE-IMPLEMENTATIONFII FSAIDITED } \\
\mathbf{( N = 1 8 6 )}\end{array}$ & $\begin{array}{l}\text { POST-IMPLEMENTATION FILESAUDITED } \\
\mathbf{( N = 1 8 6 )}\end{array}$ \\
\hline WARD A & $33(\mathbf{1 8 \% )}$ & $21(11 \%)$ \\
\hline WARD B & $25(13 \%)$ & $43(23 \%)$ \\
\hline WARD C & $26(14 \%)$ & $36(19 \%)$ \\
\hline WARD D & $40(22 \%)$ & $18(10 \%)$ \\
\hline WARDE & $39(21 \%)$ & $17(9 \%)$ \\
\hline WARD F & $23(12 \%)$ & $51(27 \%)$ \\
\hline
\end{tabular}


- An initial patient assessment on admission.

- A patient-care plan in place within 24 hours of admission and based on initial assessment.

- Nursing interventions and prescriptions relevant to prioritised problems.

- Implementation of the planned nursing care according to the identified nursing care plan.

- $\quad$ Records complying with legal requirements relating to patient documentation.

Audits were done to determine if the nursing care was planned and executed appropriately according to the requirements of the nursing process. Documentation of the following was also assessed:

Evidence that the:

- Appropriate people were informed of changes in the patient's condition, for example date and time the medical practitioner was informed.

- Required documentation from the informed people to corroborate the nursing entries.

- Adaptations to the nursing care plan were made when the patient's condition changed.

- Recording of activities carricd out and the effects of the activities.

- Nurses' recordings at least twice in 24-hours.

- Legally acceptable documentation of the death or discharge of the patient from the unit.

- A record of the patient's final diagnosis.

- Health education given to the patient and/or family on discharge.

- Medication given to the patient to take home, recorded on discharge.

The accepted standard result for all variables and the instrument total score was set at $95 \%$ by the researcher to ensure that there is a $95 \%$ confidence that the results did not occur by chance (De Poy \& Gitlin, 2005:233).

\section{Pilot study}

A pilot audit was conducted under similar circumstances as the actual study.

Figure 2: Completion of all sections of the assessment form

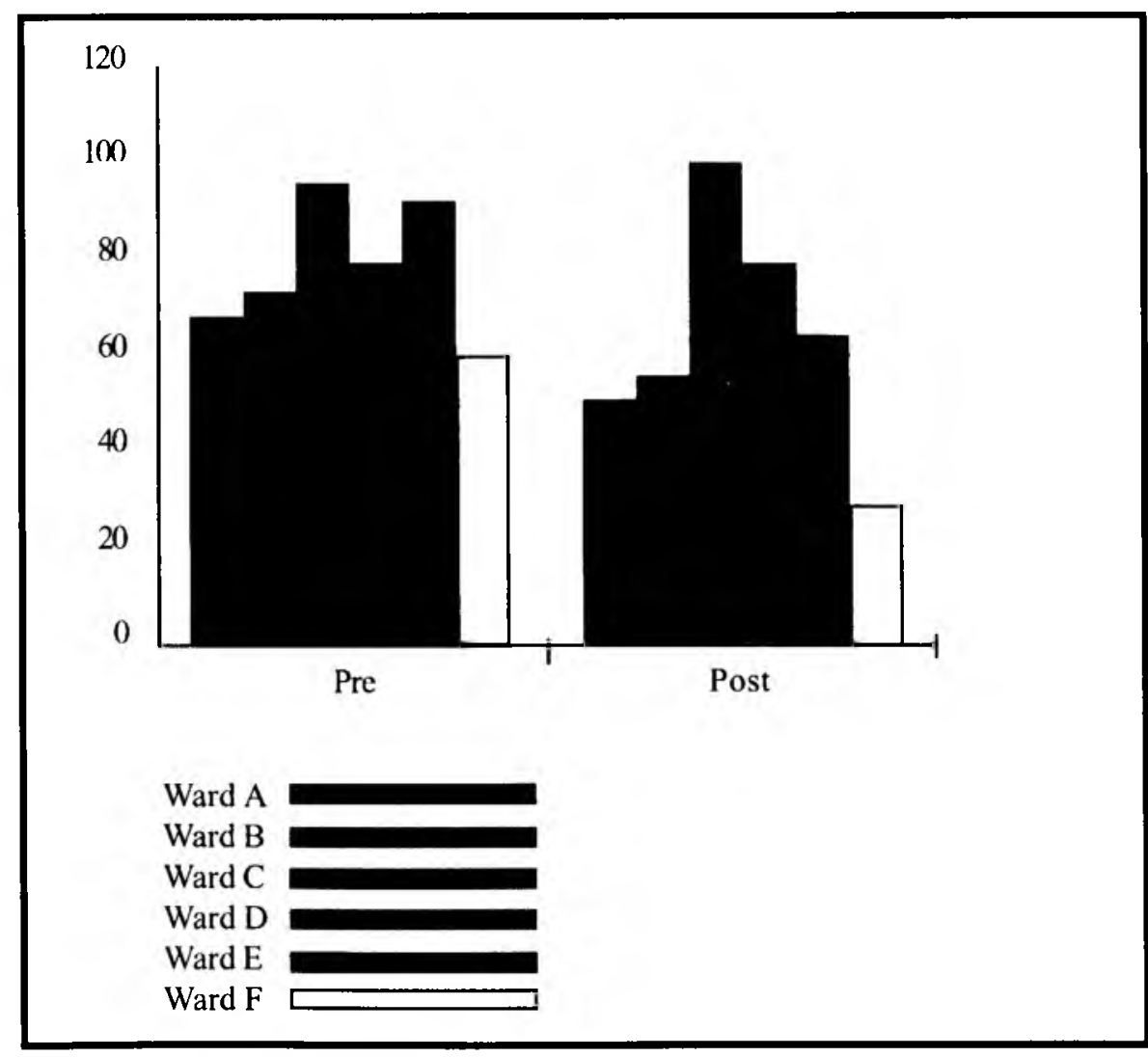

A sample of $40(10 \%)$ files, 20 pre and 20 post implementation was audited of the total number of 400 participants initially planned for the study. No revisions for the auditing instrument or the procedure were deemed necessary.

\section{Validity and reliability}

Experts in nursing, research methodology, statistics and quality assurance evaluated the modified instrument and felt that it had adequate construct validity. The validity and reliability was further supported by a pilot study.

\section{Ethical considerations}

Ethical approval for the research was obtained from the University of Stellenbosch and the ethics committee of the hospital under study. Confidentiality and anonymity of records were maintained providing only access to the researcher and kept in a locked cupboard.

\section{Data collection procedure}

Files were categorised according to date and ward. The researcher personally audited all files using the adapted audit instrument. The audit instrument was developed by the quality assur- ance manager of the hospital for use by the quality assurance committee. The standard of acceptable care was modified from 75 to $95 \%$. The objectives and evaluation explanations were deleted, as the researcher was auditing the files herself. Language was corrected. The items included on the instrument are noted under the section Audit Instrument.

\section{Data analysis}

Assisted by a statistician, the Statistical Package for the Social Sciences (SPSS) was used to analyse the quantitative data.

Data was expressed in frequencies, tables, and histograms. Statistical correlations using the Chi-square test for statistical significance between various variables on a $95 \%$ confidence level were done.

\section{Results}

No statistically significant results were found between nursing care before and after the implementation of the staffing strategy. A deterioration of results after the implementation was observed.

\section{Assessment}

Despite the fact that assessments were 
mentation.

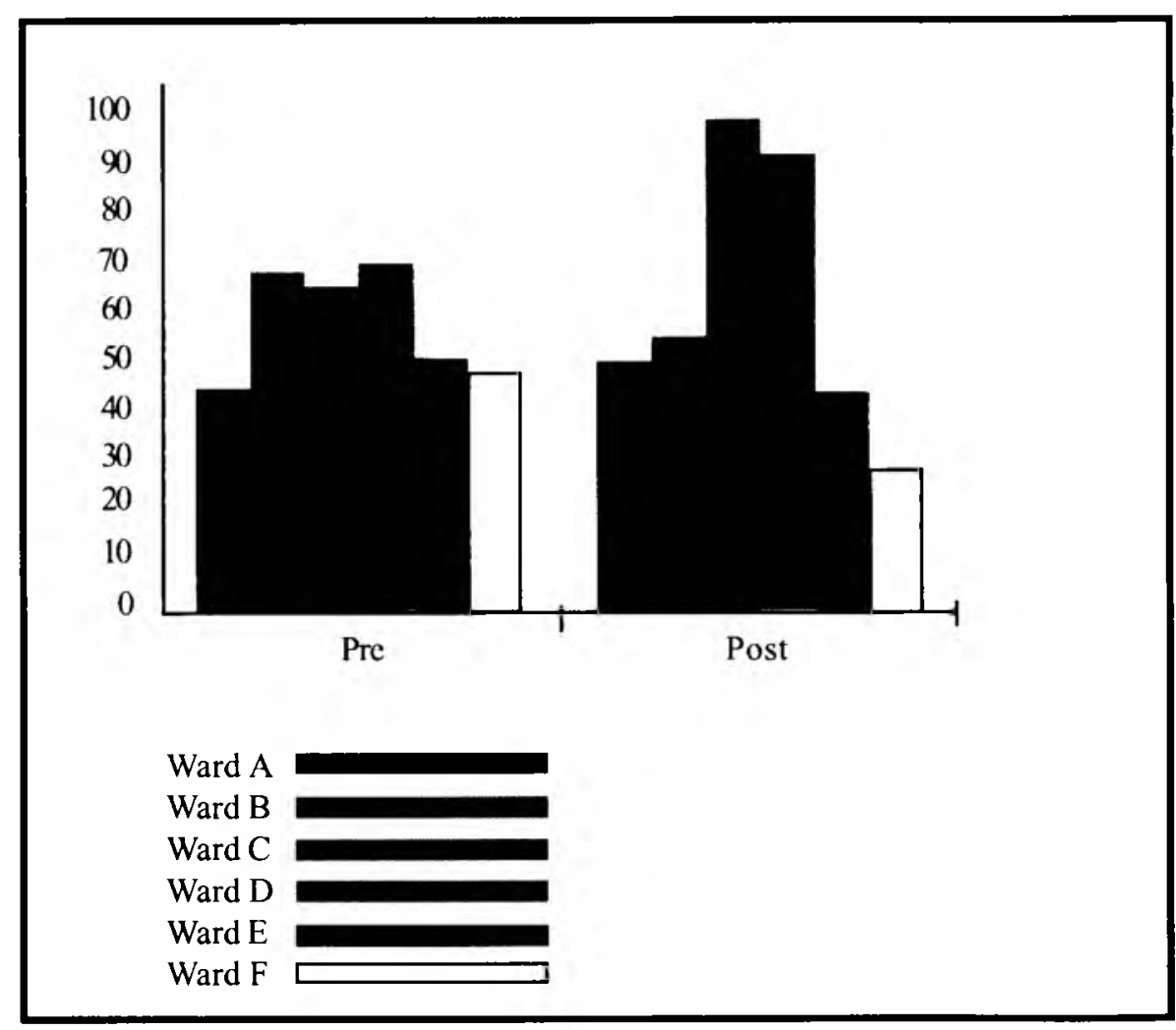

Figure 4: Specification of the initiation and resolution of the related problem by nursing prescriptions

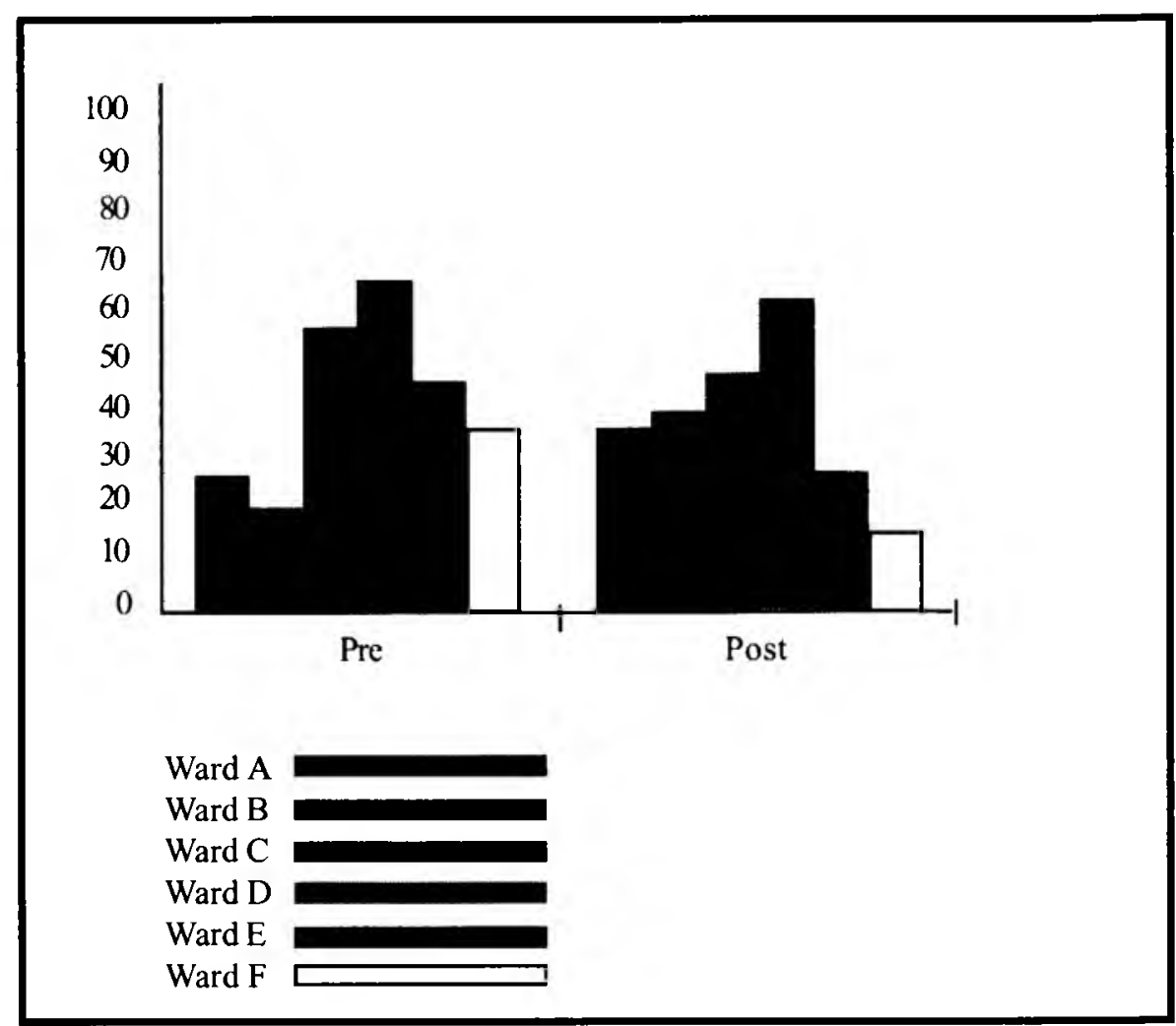

completed within 24 hours of admission, Figure 2 shows that documentation both before and after the strategy implementation was incomplete for four of the six wards. Information required about the discharge of patients was not done. Wards C $(100 \%)$ \& D which used standardised documentation, complied by completing all the sections of the assessment. Deterioration is evident for ward E, from $60 \%$ before implementation to $30 \%$ after the strategy imple-

\section{Nursing Diagnosis}

Nursing diagnoses were not made according to data identified in assessments, nor were realistic expected outcomes for the nursing care plans set. Figure 3 shows post-implementation deterioration in making nursing diagnoses in wards $\mathrm{E}$ and $\mathrm{F}$, while wards $\mathrm{C}$ and $D$ showed improvement. These findings suggest that professional registered nurses did not supervise patient care or display accountability. The scope of practice of professional registered nurses requires them to make a nursing diagnosis, formulate a nursing prescription and ensure that the prescription is implemented, evaluated and reassessed.

\section{Planning}

Nursing prescriptions showed no initiation and resolution of problems initially or daily. The nursing care plans were not congruent with assessments and problems identified. These findings suggest a lack of critical analytical skills in understanding associations between assessment, nursing diagnosis and the planning phase.

There were often no set prescriptive nursing orders nor did they specify procedures required to bring about expected outcomes. Nursing care plans were repetitive. Figure 4 shows deterioration in nursing care planning postimplementation for four of the six wards. Again wards C and D showed better planning than the other wards, which could be attributed to the standard care plans used by professional registered nurses in these two wards, but the care deteriorated after implementation. The results revealed that professional registered nurses in Wards $A, B, E$ and $F$ were not supervising the writing of care plans and failed to co-sign the plans.

Figure 5 shows that recorded nursing actions did not show association with the nursing actions prescribed in nursing care plans. Actions were performed without plans and plans were not amended as problems were resolved and new problems were identified.

Figure 6 shows professional registered nurses were not counter-signing nursing interventions. According to the Nursing Act No 33 of 2005 Professional registered nurses are accountable for the provision of nursing care; the fact 
Figure 5: Level of associations of recorded nursing actions with the nursing actions as prescribed in the nursing care plan
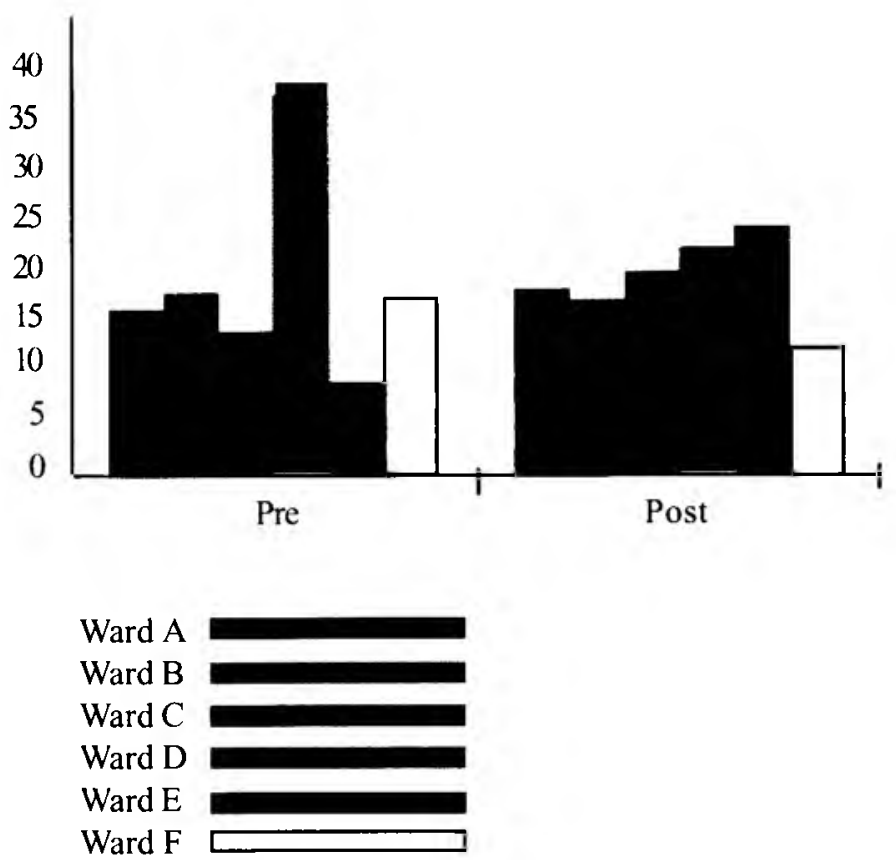

Figure 6: Follow-up and counter-signing of nursing interventions by professional registered nurse

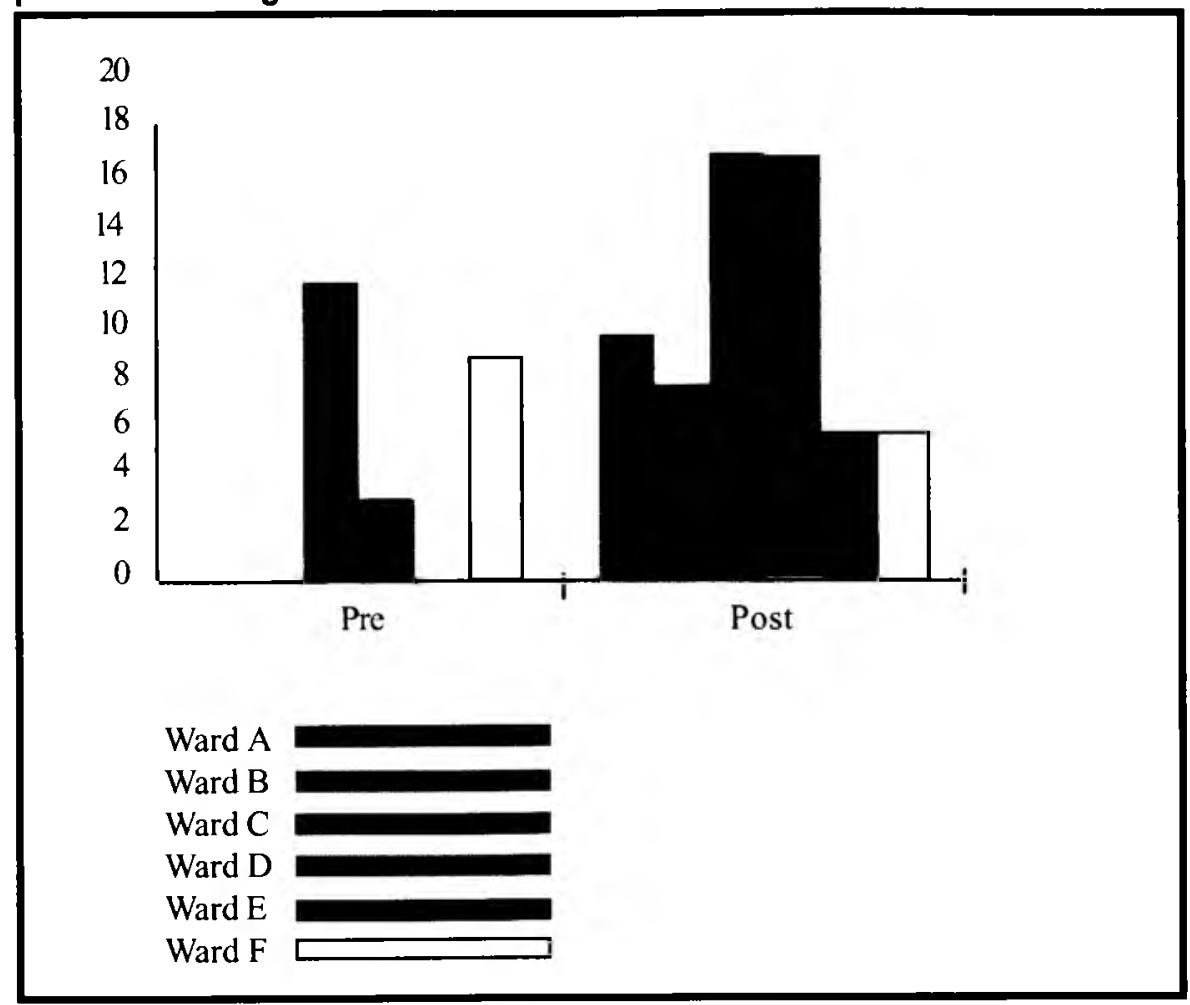

that there was little evidence of their countersigning nursing interventions, indicates a lack of accountability and poor quality of care delivered. The sample of records of wards not indicated on the graph had no record at all of professional nurses countersigning nursing interventions

Evaluation Figure 7 shows amendments to nursing care plans were not recorded and therefore not done. Despite a slight improvement after the staffing strategy was implemented, the overall results were poor. The amendments to nurs- ing care records changed from $8.6 \%$ pre - implementation to $19 \%$ post implementation. Ward $\mathrm{F}$ deteriorated postimplementation. The findings indicate that evaluation of nursing care cannot be done without nursing intervention. Despite inadequate nursing care plans, nursing records were evaluated at least twice in 24 hours and patient progress reports were concise and clear in respect of condition change and the dates and times doctors were called. The sample of records of wards not indicated on the graph had no record at all of recording amendments to nursing care plans.

\section{Discharge, Transfer or Death}

Figure 8 shows most of the records were illegal. A final written report is essential for discharge criteria and health education provided. Final assessments of patients' skin condition, vital signs, mobility and resolution of initial problems were poor, i.e. at or below $20 \%$ both pre- and post-implementation of the staffing strategy. The sample of records of wards not indicated on the graph had no record at all of recording adaptations to nursing care plans.

Figure 9 shows no medication and dressings education was given to patients on discharge. No ward performed at an acceptable level (over $95 \%$ ). The sample of records of wards not indicated on the graph had no record at all of recording final assessment of patients on discharge.

Little evidence was found in the records of relatives informed about the death, transfer or discharge of their relatives. After implementation, a change from $12.8 \%$ to $29 \%$ occurred, but the overall results were poor.

With the exception of ward D, neither the dates, times of discharge / death, nor the final diagnosis were recorded. Neither were final assessments and patients/relatives receiving back personal belongings documented. The sample of records of wards not indicated on the graph had no record at all of recording relatives being informed.

\section{Recommendations}

\section{Quality assurance}

The study shows that the quality of nursing care in most wards deteriorated after implementation. The staffing strat- 
Figure 7: Recording of adaptations to the nursing care plan

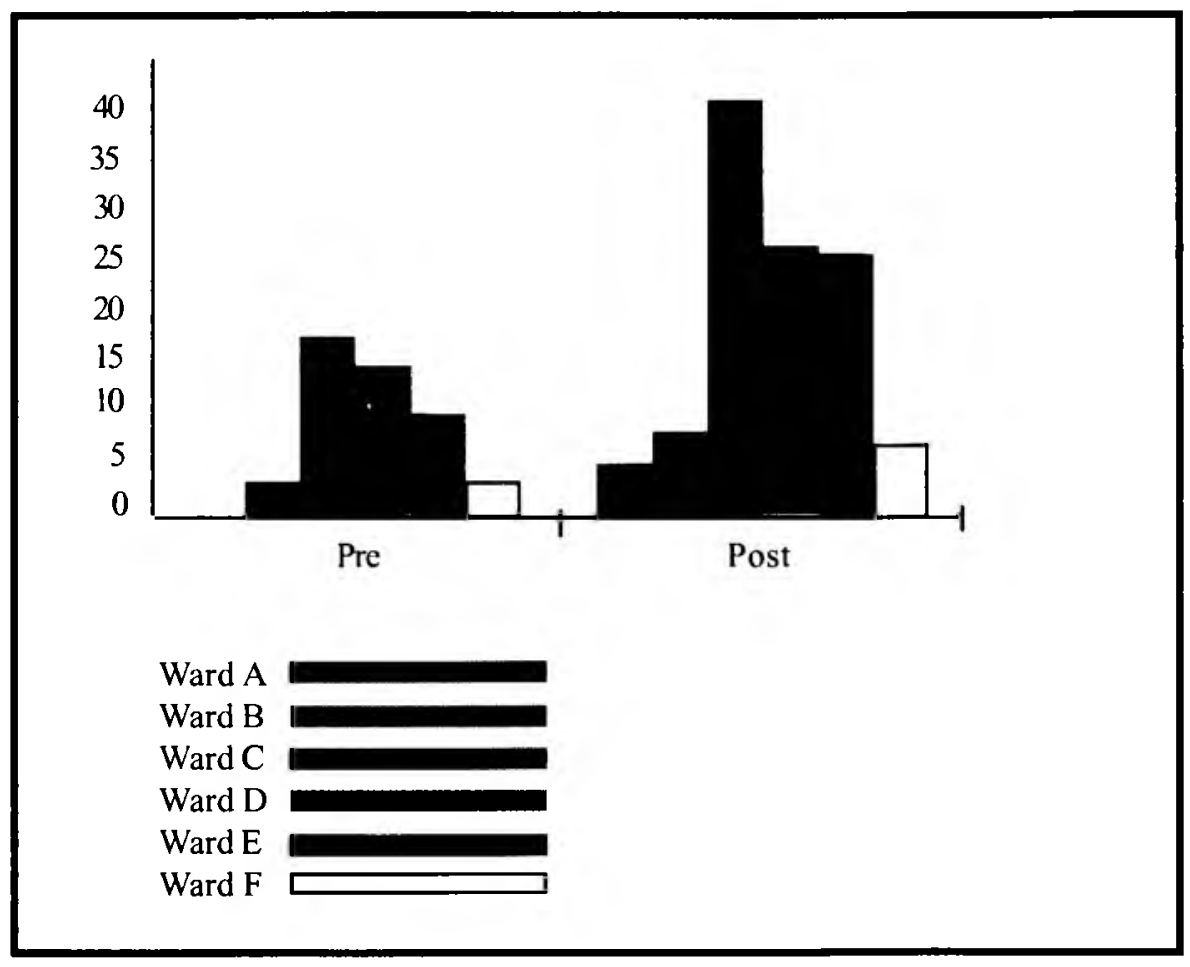

Figure 8: Documentation of final patient assessment by the nurse

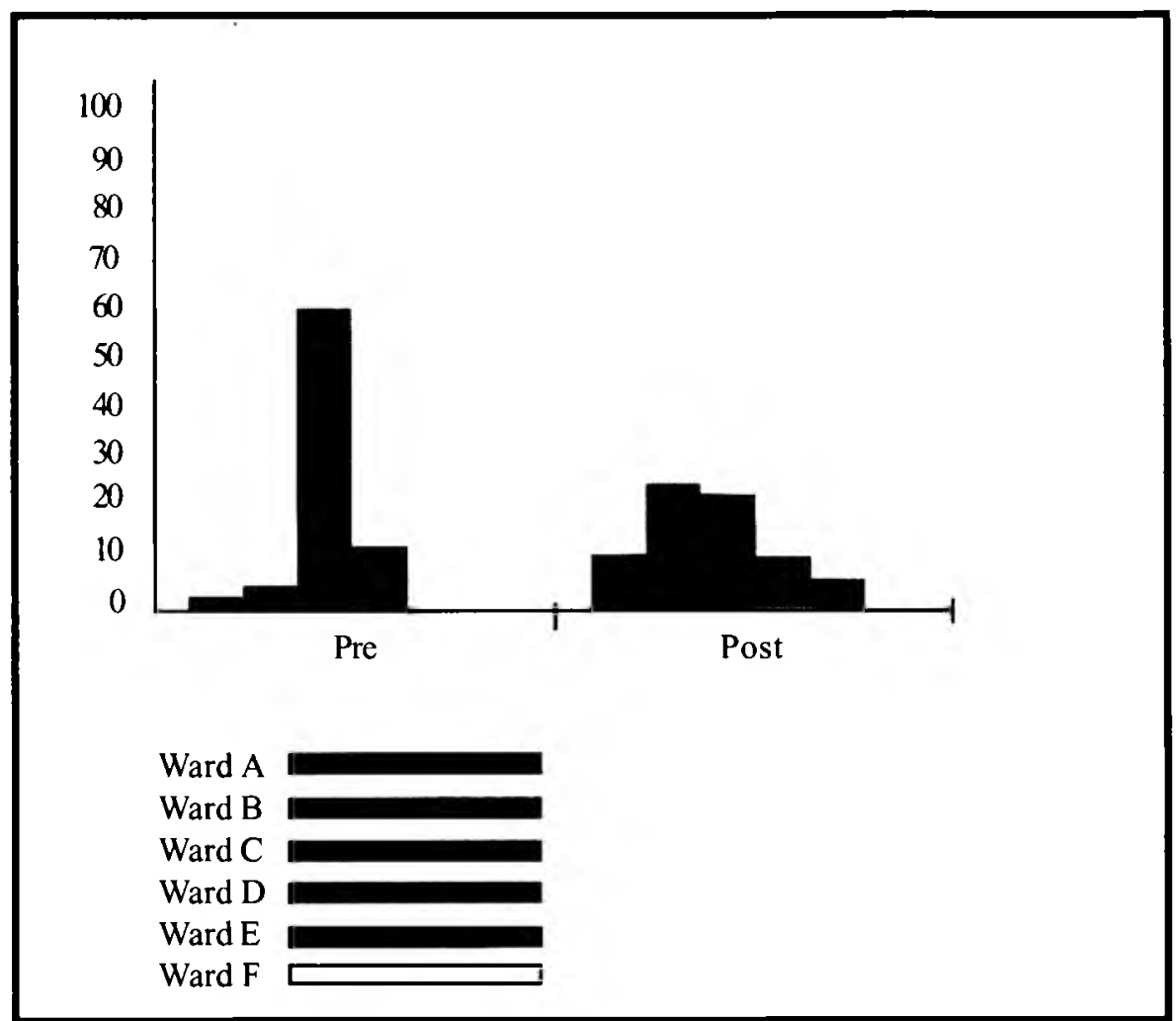

egy failed to improve or maintain the quality of nursing care. It is therefore, recommended that:

- This staffing strategy is applied with discretion. Strict controls must be in place, where the hours of work of nurses work- ing the extra ten (10) hours a week are strictly monitored. Put measures in place, to use nurses in the organization rather than "moonlighters" enabling one to control the working hours of nurses. Implement a recruitment strategy to alleviate the need for nurses to work the extra ten hours.

- Provide leadership to develop, manage and improve the professional registered nurses performance by conducting strategic planning with quality care as the focus.

- Establish a quality assurance committee to monitor the quality of patient care, e.g. document audits, infection control, patient satisfaction surveys and negative incidents. Measure whether the objectives set are achieved.

\section{Human Resource Management}

Development and up-skilling of staff are crucial to developing critical analytical thinking skills needed to improve patient care. The following steps are recommended:

- Encourage participation at all levels of decision making.

- Introduce a mentorship programme to support nursing staff with nursing practice.

- $\quad$ Formulate a policy for in-service education; include orientation and induction programmes where record keeping and nursing practice are primary topics. Evaluate record keeping knowledge of practicing nurses during employment interviews and during performance appraisals. Hold nurses accountable after quality audits through disciplinary action.

\section{The nursing process}

Introduce standardised nursing process documentation, especially nursing care plans, which through repetition, encourage decision-making and problem-solving skills. Nurse educators should emphasise the nursing process and the skills of decision making and problem solving. Holistic, individualised care for each patient must become a standard. The nursing process should be used as a practical teaching tool when teaching disease processes and professional practice.

\section{Record keeping}

The records are legal documents which must show accurate and honest nursing activities performed, reflect ac- 
Figure 9: Documentation regarding dressings or medication handed to the patient or relatives

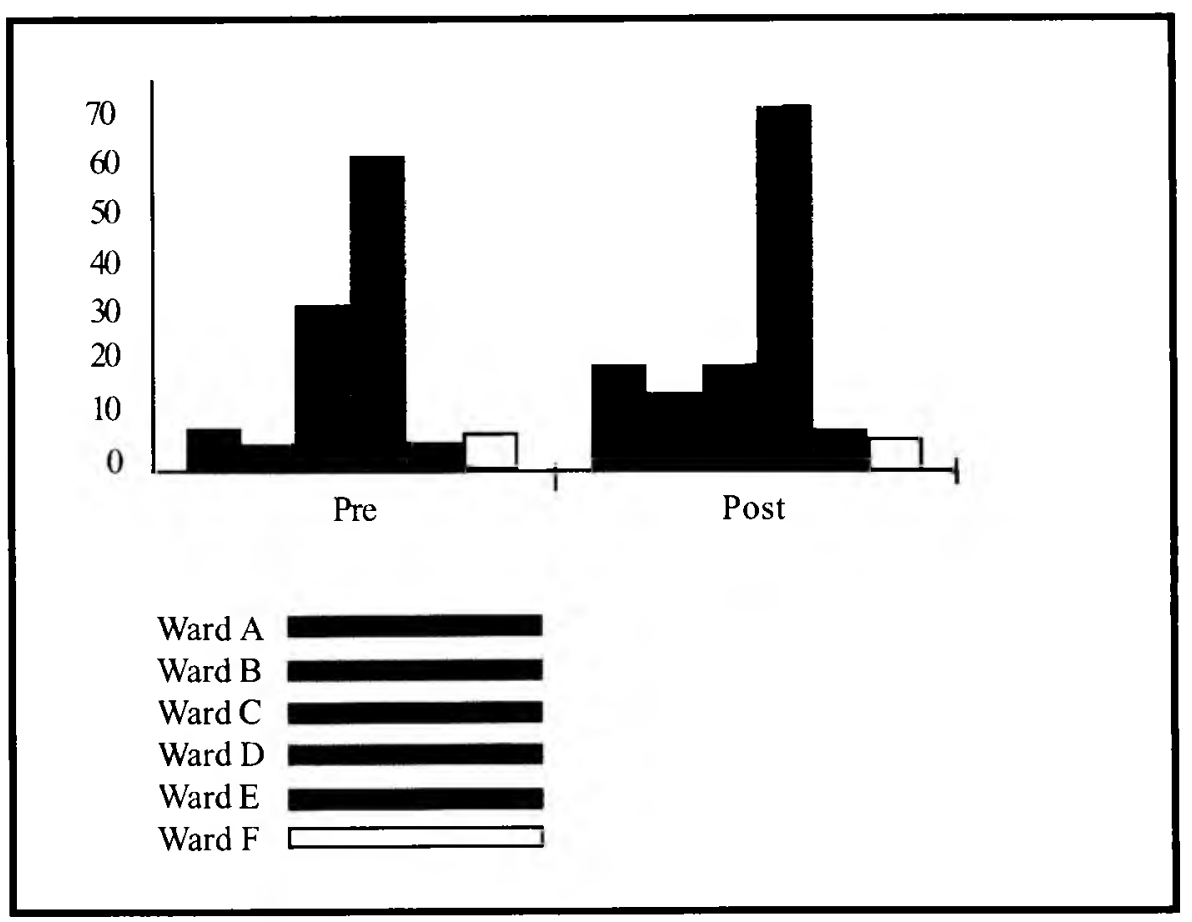

\section{Figure 10: Relatives informed about death, transfer or discharge informed about death, transfer or discharge}

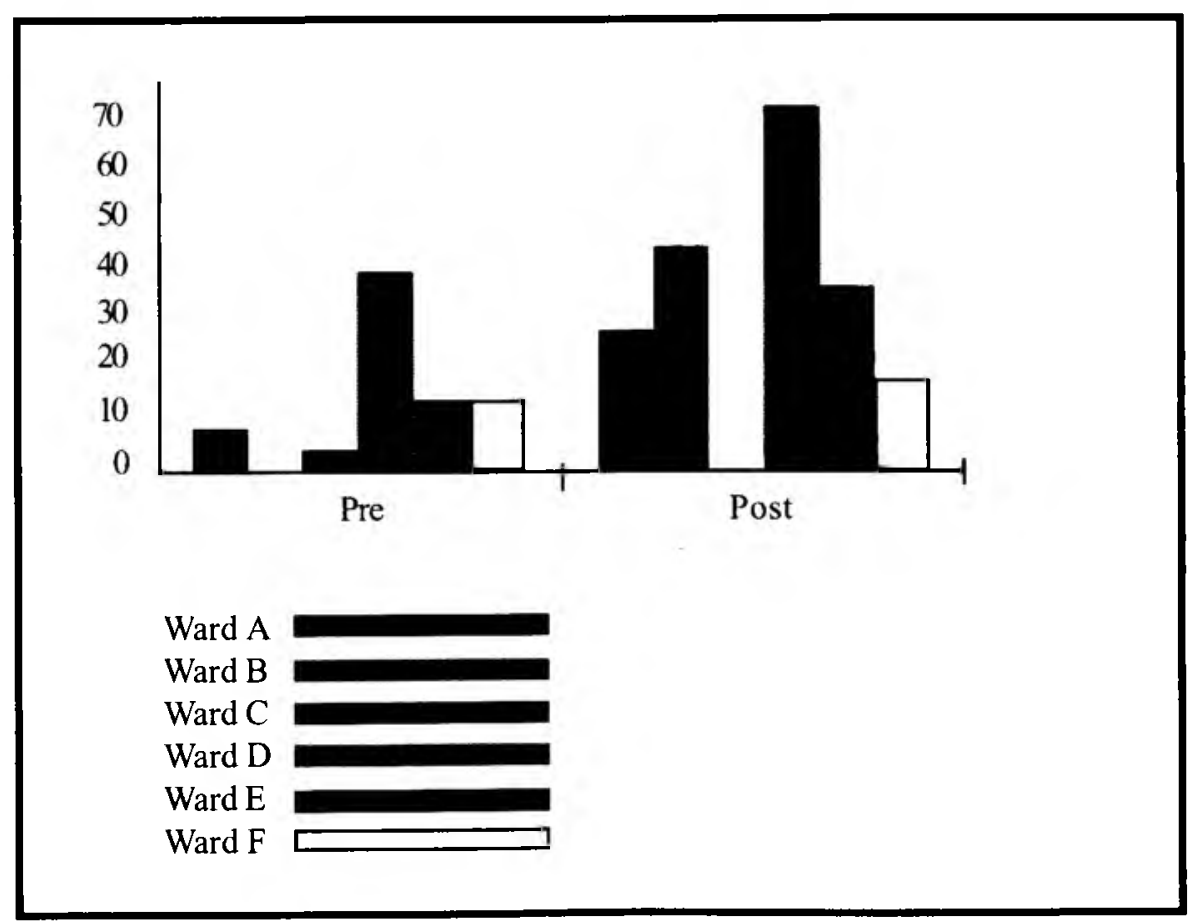

countability and provide proof that the nursing care was in fact carried out. Any negligence regarding record keeping should be acted upon.

\section{Conclusion}

The results of the study indicate that the audit instrument measured the vari- deterioration was noted in all phases of the nursing process in all wards post-implementation of the staffing strategy. The structure standards of the quality assurance programme put in place by the employer were compliant with expected standards, as a policy was in place for the nursing process to be used as a basis of record keeping, however, the process standards, namely assessment, planning, implementation and evaluation were inadequately addressed having a detrimental effect on the outcome standards, which was evident from the results of the study.

The implementation of the strategy for nurses to work an additional number of hours may have solved the shortage of staff in the short term, but the physical exhaustion and mental fatigue of the staff were not accounted for. Consequently, it had an adverse effect on the delivery of quality care. The evidence shows that using people to work extra hours to compensate for the lack of staff, may increase employment costs, the potential for litigation and dissatisfied clients.

\section{References}

BERRETTA, R 2003: Assessment: The foundations of good practice (In Hinchliff, S Norman, S \& Schober, J eds. 2003: Nursing practice and health care. London: Arnold. pp. 122)

BOOYENS, SW \& MINNAAR, A 2004: The control of quality (In Booyens, SW, ed. 2004: Introduction to health services management. Pretoria: Juta, pp.303-339)

BURNS, N \& GROVE, SK 2007: Understanding nursing research. Building an evidence - based practice. $4^{\text {th }} \mathrm{ed}$. St Louis: Saunders Elsevier.

DE POY, E \& GITLIN, LN 2005: Introduction to research: understanding and applying multiple strategies. Chicago: Mosby.

ables as was intended, including the phases of the nursing process and defining the degree of quality of the nursing care delivered in the hospital.

The professional registered nurses appeared ethically incompetent, and negligent, including the nursing managers. Despite the implementation of a strategy in overcoming the shortage of staff,
DONABEDIAN, A 1969: Medical care appraisal-quality and utilization. A guide to Medical Administration. New York: American Public Health Association.

FRANK, B; ECKRICH, H \& ROHR, J 1997: Quality nursing care: leadership 
makes the difference. JONA. 27(5):1314 , May

FRYER, N 2003: Principles of Professional Practice (In Hinchliff, S Norman, S \& Schober, J eds. 2003: Nursing practice and health care. London: Arnold. pp. 31)

GEYER, N 2006: The high risk of low staffing. Nursing Update. 30(4): 46, April

McINTOSH, J 2008: An Investigation into a Staffing Strategy in a selected Hospital in Kwa-Zulu Natal. Stellenbosch: University of Stellenbosch (Thesis - M-Cur).

MULLER, M 2004: Nursing Dynamics. Pretoria: Heinemann Publishers (Pty) Ltd.

MULLER, M; BEZUIDENHOUDT,M \& JOOSTE, K 2006: Healthcare Service Management. Cape Town: Juta.

NEVHUTALU, K 2004: The state of nursing in South Africa: a time to reflect. Nursing Update, 28(5):30-31, May

INTERNATIONAL COUNCIL OF NURSES 2007a: Occupational Health and Safety Management Programme for Nurses. http://www.icn.ch/ guidelines.htm. Accessed June 14, 2008

INTERNATIONAL COUNCIL OF NURSES.2007b: Nurses and Overtime. $\mathrm{h} \mathrm{t} \mathrm{t} \mathrm{p}: / / \mathrm{w} \mathrm{w} w . \mathrm{i} \mathrm{c}$. $\mathrm{ch} /$ matters_overtime.htm. Accessed June 14,2008

PATIENT RIGHTS CHARTER: $\underline{\text { htto: }: / /}$ www.doh.gov.za/docs/legislation/ patientsrigh $/$ chartere.html Accessed 24 November 2007.

PRONOVOST, P; ANGUS, DC; DORMAN, T et al. 2002: (In Occupational Health and Safety Management Programme for Nurses. International Council of Nurses. 2007a: http:// www.icn.ch/guidelines.htm. Accessed June 14, 2008

SEARLE, C 2000: Professional practice: a South African nursing perspective. Pretoria: Heinemann Publishers (Pty) Ltd.
The Basic Conditions of Employment Act, (Act 75 of 1997) Pretoria: Government Printer.

SOUTH AFRICA (REPUBLIC) 1996: Constitution of South Africa, (Act 108 of 1996) Pretoria: Government Printer.

SOUTH AFRICA(REPUBLIC) 1978: The Nursing Act, (Act 50 of 1978, as amended) Pretoria: Government Printer.

SOUTH AFRICA(REPUBLIC) 2005: The Nursing Act (Act 33 of 2005). Pretoria: Government Printer.

SOUTHAFRICA (REPUBLIC) 1997: White paper on Transforming Public Service Delivery: (Batho Pele White Paper), 18340(388). Pretoria: Government Printer.

TROSKIE, R 2005: Organizing facilities, equipment and supplies, (In Booyens, SW, ed. $2^{\text {nd }}$ Ed. 2005: Introduction to health services management. Pretoria: Juta, pp.260 - 283)

THE SOUTH AFRICAN NURSING COUNCIL Undated: Standards for Nursing practice. South African Nursing Council policy statements.

THE SOUTH AFRICAN NURSING COUNCIL 1984: Regulation 2598 as amended. Regulations relating to the Scope of Practice of persons who are registered or enrolled under the Nursing Act No 50 of 1978. Pretoria: South African Nursing Council.

THE SOUTH AFRICAN NURSING COUNCIL 1985: Regulation 387 as amended. Regulations relating to the Acts and Omissions of persons who are registered or enrolled under the Nursing Act No 50 of 1978. Pretoria: South African Nursing Council.

VERSCHOOR, T; FICK, GH; JANSEN, RM \& VILJOEN, DJ 2005: Nursing and the Law. Cape Town: Juta.

YOUNG, A; VAN NIEKERK, CF \& MOGOTLANE, S eds. 2003: Juta's manual of nursing. Cape Town: Juta.

ZONDAGH, C 2004: Safe and adequate nurse staffing. Nursing Update. 28(5):20-24. May 